\title{
A Comparative Study on Effect of Inhaled Salbutamol and Ipratropium Bromide on the Bronchomotor Tone in Normal Young Adults
}

\author{
Dr. Sharada Mayee Swain ${ }^{1}$, Dr. BibhupadaMahapatra ${ }^{2}$, \\ Dr. Bipin BihariPradhan ${ }^{3}$ \\ I'Post Graduate Student, Department of Physiology, M.K.C.G Medical College, Berhampur,Odisha, India) \\ ${ }^{2}$ (Associate Professor, Department of Physiology, M.K.C.G Medical College, Berhampur, Odisha, India) \\ ${ }_{3}^{3}$ (Professor and Head, Department of Physiology, M.K.C.G Medical College, Berhampur,Odisha, India)
}

\begin{abstract}
The regulation and fine tuning of airway caliber is basically determined by the bronchial tone through airway smooth muscle contraction and relaxation, wherein the autonomic nervous system has an important role. Here, we have compared Salbutamol ( $\beta_{2}$ adrenergic agonist) and Ipratropium bromide $\left(M_{2}\right.$ muscarinic antagonist). Previous studies focused mainly on patients with COPD, emphysema, asthma etc. and they showed inconsistent results. So the present study was taken up with an objective to find out the difference between the effects of inhaled Salbutamol and Ipratropium on the bronchomotor tone in healthy adults. The study included 86 subjects of age group 17-25 years. On day one, baseline spirometry was first recorded, followed by repeat spirometry 20 min. after giving 2 puffs of Salbutamol through MDI. On day two, spirometry was done 40 min. after administering 2 puffs of Ipratropium. $F E V_{1}, M E F_{25}, M E F_{75}, M E F_{25-75}$ PEF were significantly higher after Salbutamol inhalation. PIF, MIF50were also higher with Salbutamol but not statistically significant.
\end{abstract}

Keywords: - Autonomic nervous system, Bronchomotor tone, Spirometry, MDI.

\section{Introduction}

The autonomic nervous system regulates different aspects of airway function like smooth muscle tone, secretion, blood flow, microvascular permeability and the migration and release of inflammatory cells ${ }^{(1)}$. The regulation and fine tuning of airway caliber is mainly determined by bronchial tone. There exists a sensitive balance between the two components of the ANS, the parasympathetic component being more important in regulating airway tone, while the sympathetic nervous system plays a major role in the control of airway blood flow and glandular secretion ${ }^{(2)}$.

In our study, we have compared Salbutamol, a short-acting $\beta_{2}$ agonist and Ipratropium bromide, a short-acting anticholinergic (muscarinic $\mathrm{M}_{2}$ antagonist) .

There is not much information available in medical literature regarding studies on bronchomotor tone in healthy individuals as most of the previous works were in relation to patients with $\operatorname{COPD}^{(3,4)}$, emphysema ${ }^{(5)}$, asthma ${ }^{(6)}$.The works centered on fewer number of cases and that too with limited lung function parameters. Moreover, conclusions arrived at, did not clarify the role of these bronchodilating agents in healthy subjects. So the current study was undertaken to investigate whether there is any difference between the bronchodilating effects of inhaled Salbutamol and Ipratropium and to evaluate the roles of parasympathetic and sympathetic components of the ANS in regulation of the bronchomotor tone in normal young adults.

\section{Material \& Method}

This prospective study was conducted in PG Research Lab, Dept. of Physiology, MKCG Medical College, Berhampur from Nov. 2011 to May 2013 after due approval from the IEC.

Study included 86 healthy young adults within age group 17- 25 years of both sexes.

Subjects with history of smoking, asthma, or any pulmonary disease were excluded from this study. Also excluded from the study were subjects with hypersensitivity to Salbutamol or Ipratropium.

On day one, baseline spirometrywas recorded with Windows based Flowhandy ZAN 100USB \& ZAN

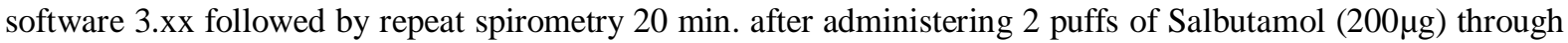
MDI. On day two, 2 puffs of Ipratropium bromide $(40 \mu \mathrm{g})$ was given through MDI and spirometry done after 40 min.

The data obtained were analyzed by using single factor ANOVA (analysis of variance).

A $\mathrm{p}$ value less than 0.05 was taken as statistically significant. 


\section{Observation \& Analysis}

Table-1

\begin{tabular}{|l|l|l|l|l|l|}
\hline Static Lung Parameters \\
\hline & ERV (Lit.) & IRV (Lit.) & TV (Lit.) & VC (Lit.) & IC (Lit.) \\
\hline Base line & $0.79 \pm 0.43$ & $2.28 \pm 0.79$ & $0.89 \pm 1.04$ & $3.96 \pm 0.67$ & $3.17 \pm 0.71$ \\
\hline Salbutamol & $2.91 \pm 12.02$ & $2.46 \pm 0.78$ & $0.80 \pm 0.80$ & $4.00 \pm 0.74$ & $3.10 \pm 0.64$ \\
\hline Ipratropium bromide & $0.84 \pm 0.40$ & $2.38 \pm 0.484$ & $0.77 \pm 0.91$ & $4.28 \pm 0.22$ & $3.11 \pm 0.64$ \\
\hline p Value & 0.33 & 0.64 & 0.84 & $0.05 *$ & 0.89 \\
\hline
\end{tabular}

Figure-1
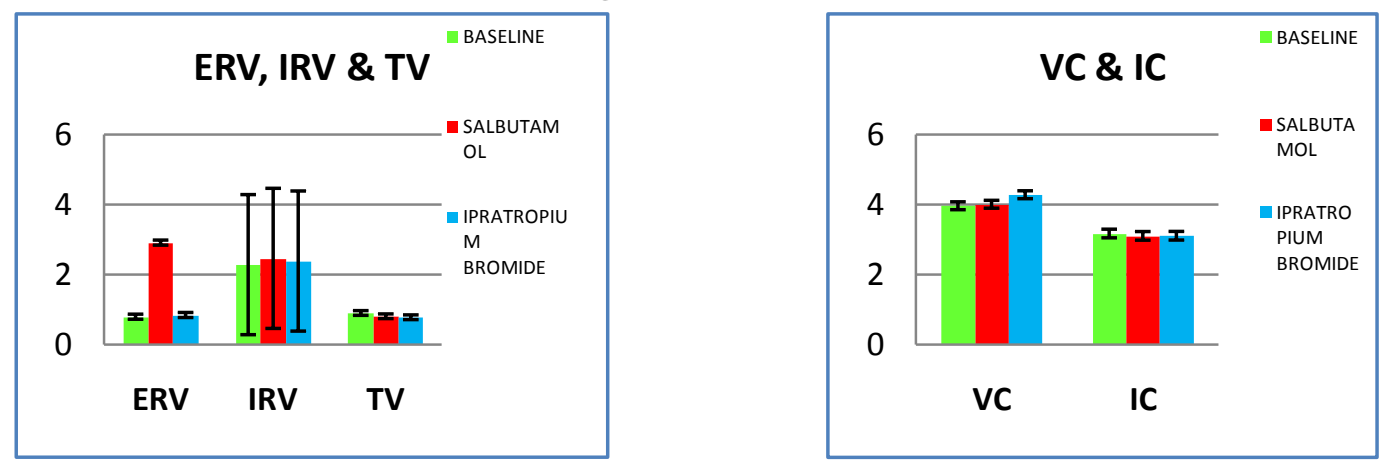

Table-2

\begin{tabular}{|l|c|c|}
\hline \multicolumn{3}{|c|}{ Dynamic Lung Function Parameters } \\
\hline & FVC (Lit.) & FEV1 (Lit.) \\
\hline Base line & $3.82 \pm 0.66$ & $3.54 \pm 0.60$ \\
\hline Salbutamol & $3.82 \pm 0.74$ & $3.94 \pm 0.74$ \\
\hline Ipratropium bromide & $3.78 \pm 0.70$ & $3.51 \pm 0.55$ \\
\hline p Value & 0.95 & $0.008^{*}$ \\
\hline
\end{tabular}

Figure-2

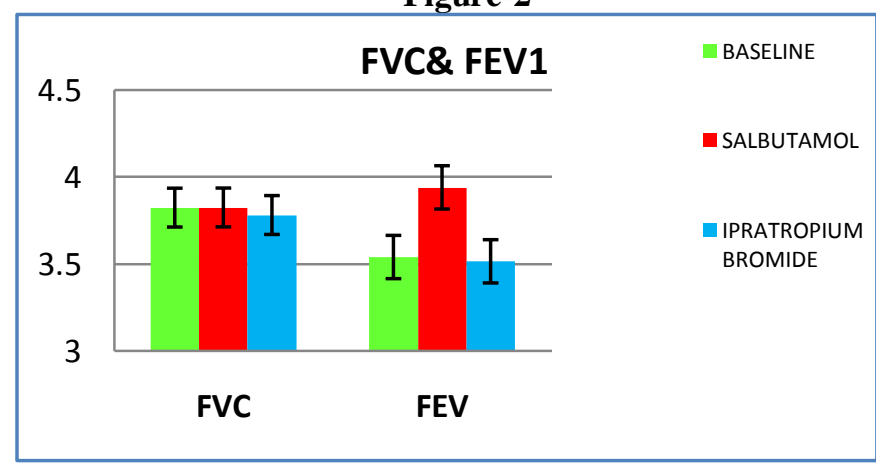

Table- 3

\begin{tabular}{|l|l|}
\hline \multicolumn{2}{|c|}{ Dynamic Lung Function Parameter } \\
\hline & FEV1/FVC $(\%)$ \\
\hline Base line & $92.38 \pm 4.78$ \\
\hline Salbutamol & $93.52 \pm 4.30$ \\
\hline Ipratropium bromide & $94.08 \pm 4.42$ \\
\hline p Value & 0.271 \\
\hline
\end{tabular}


Figure-3

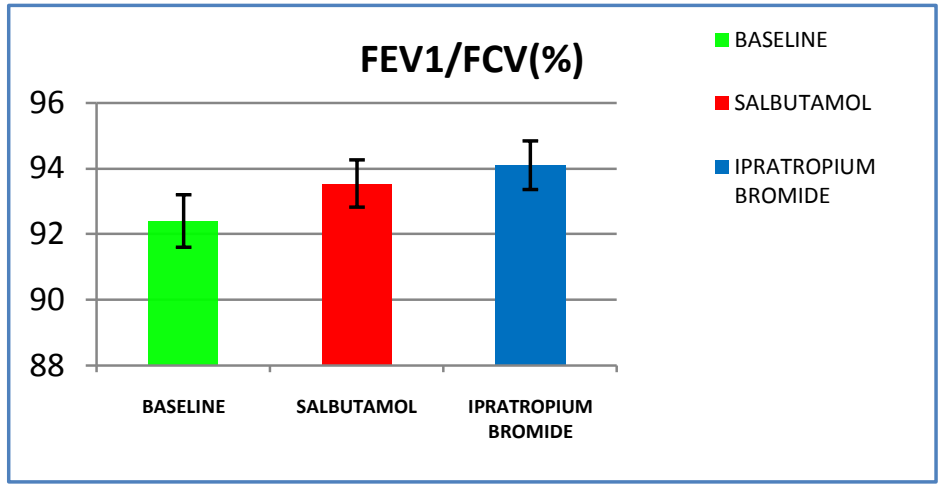

Table-4

\begin{tabular}{|c|c|c|c|c|c|}
\hline $\begin{array}{l}\text { Maximal Expiratory Flow } \\
\text { Rates }\end{array}$ & $\mathrm{MEF} 75(\mathrm{~L} / \mathrm{S})$ & MEF50(L/S) & MEF25(L/S) & $\begin{array}{l}\text { MEF25- } \\
\text { 75(L/S) }\end{array}$ & $\mathrm{PEF}(\mathrm{L} / \mathrm{S})$ \\
\hline Base line & $6.78+1.5$ & $5.24+1.12$ & $2.58+0.74$ & $4.60 \pm 0.96$ & $7.20 \pm 1.58$ \\
\hline Salbutamol & $7.72 \pm 1.64$ & $5.59 \pm 1.15$ & $3.07+1.11$ & $5.17 \pm 1.19$ & $8.24+1.52$ \\
\hline Ipratropium bromide & $6.74 \pm 1.42$ & $5.43+1.03$ & $2.65 \pm 0.65$ & $4.69 \pm 0.86$ & $7.62+1.53$ \\
\hline p Value & $0.011 *$ & 0.397 & $0.037^{*}$ & $0.042 *$ & $0.019 *$ \\
\hline
\end{tabular}

Figure-4

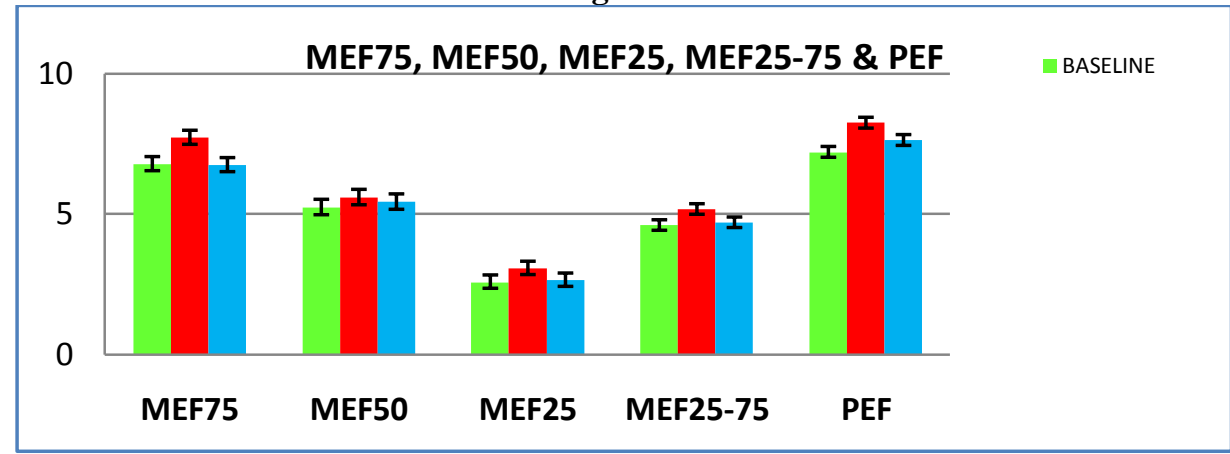

Table-5

\begin{tabular}{|l|l|l|}
\hline Inspiratory flow rates & PIF(L/S) & MIF50(L/S) \\
\hline Base line & $6.41 \pm 1.90$ & $6.14 \pm 1.82$ \\
\hline Salbutamol & $6.77 \pm 2.25$ & $6.42 \pm 2.25$ \\
\hline Ipratropium bromide & $6.74 \pm 1.69$ & $6.30 \pm 1.81$ \\
\hline p Value & 0.686 & 0.828 \\
\hline
\end{tabular}

Figure-5

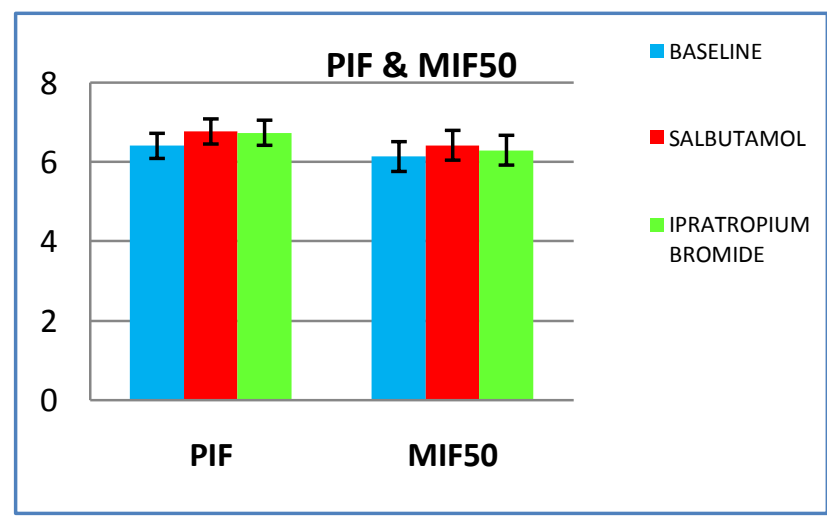




\section{Discussion}

The distribution and density of adrenergic and cholinergic receptors in the tracheobronchial tree determine the site of action of the various bronchodilators.

Of the static lung parameters, vital capacity showed higher increase with Ipratropium bromide. (Table-1, Figure1)

Dynamic parameters like $\mathrm{FEV}_{1}, \mathrm{MEF}_{25}, \mathrm{MEF}$ 75, $\mathrm{MEF}_{25-75}$, PEF were significantly higher after Salbutamol inhalation as compared to Ipratropium. (Table- 2,4 and Figure- 2,4) The inspiratory flow rates i.e.

PIF, MIF50 also showed more improvement with Salbutamol than that of Ipratropium, but it was not statistically significant. (Table-5, Figure-5). In humans, studies that have tried to distinguish large and small airway effects have shown that cholinergic bronchoconstriction predominantly involves larger airways ${ }^{(7)}$, whereas $\beta$-adrenergic agonists are equally effective in large as well as small airways ${ }^{(8)}$

The close proximity of bare putative cholinergic and adrenergic varicosities within small nerve bundles in bronchi of humans provides a structural basis of prejunctional control ${ }^{(9)}$

(a) $\quad \mathrm{M}_{2}$ muscarinic autoreceptors inhibiting acetylcholine release and

(b) $\quad \beta_{1}$ and $\beta_{2}$ adrenergic heteroreceptors inhibiting cholinergic release

The enhanced response of Salbutamol over Ipratropium may be due to its prejunctional inhibition of cholinergic transmission. Corroborative studies also show that in young, Salbutamol is more effective a bronchodilator than Ipratropium compared to the elderly. ${ }^{(10,11)}$

It might be due to a progressive decrease of $\beta$ adrenoreceptor function, responsiveness and number with age as is thought to occur with human cardiac and neural tissues ${ }^{(12,13)}$

\section{Conclusion}

Our study shows that inhaled Salbutamol is a better regulator of bronchodilation than Ipratropium bromide in young healthy subjects and this has important therapeutic implications.

\section{References}

[1]. Barnes PJ: Neural control of human airways in health and disease. Am Rev Respir Dis (1986) 134: 1289-1314.

[2]. Barnes PJ, Fitzgerald G, Brown M, Dollery C (1980). Nocturnal Asthma and changes in Circulating epinephrine, histamine, cortisol, New Eng J Med, 303, 263-7.

[3]. S.K Chhabra, V.K. Vijayan and T.Vasu: Inhaled Formoterol versus Ipratropium Bromide in COPD, Indian J Chest Disease Allied Science : 2006: 48; 97-102

[4]. Kerpel J.P, Bronchodilator responses to anticholinergic and beta-adrenergic agents in acute and stable COPD, chest. 1991: 99, 876

[5]. Hughes J A, Tobin M J,BellamyD,Hutchinson D C. Effects of Ipratropium bromide and Fenoterol aerosols in pulmonary emphysema.Thorax 1982;37,667-670.

[6]. Van Schayck C P, FolgeringH,Mass K L,VanWeel C; Effects of allergy and age on responses to Salbutamol and Ipratropium in moderate asthma and chronic bronchitis. Thorax;1991,46,355-359.

[7]. Richardson J B; Nerve supply to the lung. Am Rev Respir Dis (1979);119,785-802.

[8]. Ingram R H J,Wellman J J,McFadden E R J,Mead J; Relative contribution of large and small airways to flow limitation in normal subjects before and after Atropine and Isoproterenol. Clin Invest (1979);59,696-703.

[9]. Jansen L J,Daniel E E; Characterization of the prejunctional beta-adrenoceptors in canine bronchial smooth muscle; PharmacoExpTher(1990);254,741-749.

[10]. L A De Backer,W G Vos,R Salgado; Functional imaging using computer methods to compare the effects of salbutamol and ipratropium in patient-specific airway models of COPD(2011).

[11]. M I Ullah,G B Newman,K B Saunders; Infleunce of age on response to Ipratropium and Salbutamol in asthma. Thorax(1981);36.523-529.

[12]. Vestal R E,Wood A J Shand D G; Reduced beta adrenoceptor sensitivity in the elderly. ClinPharmacol Ther,1979;26,181-6.

[13]. Maggi A,Schmidt M J,GhettiB,Enna S J. Effect of aging on neurotransmitter receptor binding in rat and human brain. Life Sci, 1979;24,367-74. 